\title{
Risk Factors for Placental Malaria, Sulfadoxine-pyrimethamine Doses, and Birth Outcomes in a Rural to Urban Prospective Cohort Study on the Bandiagara Escarpment and Bamako, Mali
}

\author{
Claudius Vincenz \\ University of Michigan \\ Zachary Dolo \\ Independent \\ Serou Saye \\ Independent \\ Jennie Lovett \\ University of Michigan \\ Richard W. Lieberman \\ University of Michigan Michigan Medicine \\ Beverly I.Strassmann ( $\nabla$ bis@umich.edu ) \\ University of Michigan https://orcid.org/0000-0002-3783-7977
}

\section{Research Article}

Keywords: Placenta, malaria, pregnancy, histology, birth weight, IPTp, sulfadoxine-pyrimethamine, maternal education, birth seasonality, cohort

Posted Date: January 5th, 2022

DOI: https://doi.org/10.21203/rs.3.rs-1200669/v1

License: (c) (i) This work is licensed under a Creative Commons Attribution 4.0 International License. Read Full License

Version of Record: A version of this preprint was published at Malaria Journal on March 31st, 2022. See the published version at https://doi.org/10.1186/s12936-022-04125-6. 


\section{Abstract}

\section{Background}

Malaria in Mali remains a primary cause of morbidity and mortality, with women at high risk during pregnancy for placental malaria (PM). We evaluated risk for PM and its association with birth outcomes in a rural to urban longitudinal cohort on the Bandiagara Escarpment and the District of Bamako.

\section{Methods}

We collected placental samples $(\mathrm{N}=317)$ from 249 mothers who were participants in our longitudinal cohort study. A placental pathologist and research assistant evaluated the samples by histology in blinded fashion to assess PM infection stage and parasite density. We used generalized estimating equations (GEE) to model the odds of PM infection.

\section{Results}

Pregnancies in Bamako, beyond secondary education, births in the rainy season (instead of the hot dry season), births in later years of the study, and births to women who had $\geq 3$ doses of sulfadoxine-pyrimethamine (SP) instead of no doses of SP were associated with reduced odds of experiencing PM (active and past infections combined). We found improved birth outcomes $(+285 \mathrm{~g}$ birth weight, $+2 \mathrm{~cm}$ birth length, $+75 \mathrm{~g}$ placental weight) for women who had $\geq 3$ doses of SP compared to no doses, but did not detect a difference in birth weight or length for women who had 2 instead of $\geq 3 \mathrm{SP}$ doses. However, at 2 instead of $\geq 3$ doses placentas were $36 \mathrm{~g}$ lighter and the odds of low birth weight $(<2500 \mathrm{~g}$ ) were $14 \%$ higher. Severe parasite densities were significantly associated with decreases in birth weight, birth length, and placental weight, as were chronic PM infections. The women who received no SP during pregnancy ( $7 \%$ of the study total) were younger and lacked primary school education. The women who received $\geq 3$ doses of SP came from more affluent families.

\section{Conclusions}

Women who received no doses of SP during pregnancy experienced the most disadvantageous birth outcomes in both Bamako and on the Bandiagara Escarpment. Such women tended to be younger and to have had no primary school education. Targeting such women for antenatal care, which is the setting at which SP is most commonly administered in Mali, will have a more positive impact on public health than focusing on the increment from two to three doses of SP.

\section{Background}

In 33 countries in sub-Saharan Africa in 2019, more than eleven million pregnant women were exposed to malaria infections and delivered 882,000 low birthweight neonates [1]. During pregnancy, erythrocytes infected with mature asexual $P$. falciparum parasites sequester in the placenta. Placental malaria (PM) is defined by the presence of infected erythrocytes (IE) or hemozoin in the placental intervillous space and is associated with maternal illness and anemia [2-4], low birth weight [3, 5], and preterm birth [3,5].

To prevent malaria infections in pregnant women, the WHO recommends a combination of intermittent preventive treatment in pregnancy (IPTp) with sulfadoxine-pyrimethamine (SP) as part of antenatal care (ANC), long-lasting insecticidal bed nets (LLINs) [3], and indoor residual spraying (IRS) [6]. Doses of SP are to be administered one month apart at the start of the second trimester [6] and have been effective in reducing the risk of placental malaria, low birth weight, and severe maternal anemia [7]. Eleven sub-Saharan African countries account for about $70 \%$ of the global malaria case burden and estimated deaths [3]. One of these countries is Mali, which has among the highest malaria case incidence rates at $>250$ per 1000 population at risk [3]. In 2013, the Malian Ministry of Health revised its guidelines to reflect the WHO's recommendation that at least three doses of SP should be administered to pregnant women beginning in the second trimester [8]. Despite national control efforts, in 2018 only $42 \%$ of women received the recommended three doses of SP [9], leaving a significant number of pregnant women at risk for malaria infections.

The women in this prospective cohort study were enrolled in infancy or early childhood (median age 1.36 years) on the Bandiagara Escarpment in central Mali. This 21-year study is unique for Africa in that follow-up occurred on a regular, nearly annual basis to adulthood. It is rare for an observational study that compares urban and rural participants to have a quasi-experimental design. In our study, follow-up occurred both in the rural community and after migration to Bamako, permitting comparison of risk factors in the same cohort and same ethnicity (the Dogon) in both locations. To our knowledge, this study is the first to assess risk factors for PM in Mali using placental tissue histology, and it is helpful for tracking the success of the National Malaria Control Program (NMCP) of Mali on the Bandiagara Escarpment. This study addressed the following questions: (1) Was risk for PM higher in Bamako or on the Bandiagara 
Escarpment (2) What were the maternal risk factors for PM in this cohort? (3) What was the association between number of IPTp-SP doses, PM, and birth outcomes-in particular, were there observable benefits for three instead of two doses of SP? (4) What factors predicted how many IPTp-SP doses women received?

\section{Methods}

\section{Study population and design}

Study participants ( $\mathrm{N}=832$ females) belong to the Dogon ethnic group and were enrolled in a prospective cohort study during infancy or early childhood in nine rural villages on the plateau of the Bandiagara Escarpment [10, 11]. Enrollment took place from 1998 to 2000 at a mean age of 1.36 years (range 0 to 5 years). When surviving girls $(\mathrm{N}=676)$ reached adolescence or adulthood and gave birth $(\mathrm{N}=386)$, placental tissue was collected and analyzed from 317 singleton births to 249 mothers (Figure 1). Births occurred from December 2011 to June 2019.

\section{Ethics Statement}

This study was approved by the ethics committee of The University of Bamako Medical Faculty (No. 2016/68/CD/FMPOS), the University of Michigan IRBMED (HUM00043670), the Malian government ( $N^{\circ}$ 02/ 2019-MESRS/CNRST), and the local health facilities. Informed written consent was obtained from all study participants.

\section{Histology}

Biological specimens were collected from placentas within $30 \mathrm{~min}$ of placental expulsion. Specimens for histology and nucleic acid analysis were obtained simultaneously from the two faces of a well-formed cotyledon using a mirrored sampling approach. The tissue sampled $\left(<1 \mathrm{~cm}^{3}\right)$ was from the central two-thirds of the placental surface and consisted mainly of fetal villi and maternal intervillous space. Two histological samples were dissected from two cotyledons for each placenta and fixed with $37 \%$ formalin freshly diluted 1:10 with buffered saline. Fixation was for $36 \mathrm{hrs}$ on ice followed by a $30 \mathrm{~min}$ wash in $70 \%$ ethanol followed by storage in a $-20^{\circ} \mathrm{C}$ solar freezer for up to 18 months. The samples were shipped to the University of Michigan on dry ice. Upon arrival, tissues were stored at $-80^{\circ} \mathrm{C}$, then thawed in $70 \%$ ethanol for mounting, sectioning, and haemotoxylin and eosin (H\&E) staining at the University of Michigan Tissue and Molecular Core (TMP). Giemsa stains were performed in the Strassmann laboratory. Blinded histological evaluation was performed by a placental pathologist (RL) and research assistant using established guidelines for assessment of placental malaria [12, 13]. Discrepancies between evaluators were resolved by a third consensus evaluation by both parties. Slides were scored for 6 characteristics: malaria parasites (presence and density), hemozoin pigment (presence and density), and malaria infection (none, acute, chronic, past).

\section{Definitions}

Placental malaria infection stages were classified based on histopathology as: uninfected (no parasites or pigment present); acute (parasites present in maternal erythrocytes in the intervillous space, pigment in erythrocytes and monocytes in the intervillous space but no pigment in fibrin or cells within fibrin); chronic (parasites in maternal erythrocytes in the intervillous space and pigment in erythrocytes and circulating monocytes within the intervillous space and pigment in fibrin or cells within fibrin and/or chorionic villous syncytiotrophoblast or stroma) and past (pigment confined to fibrin or cells within fibrin but no parasites present) [13]. Active infections included both acute and chronic infections but not past infections. Density of infected erythrocytes (parasitemia) was classified as not present, mild ( $<1 \%$ maternal erythrocytes infected), moderate (1-10\% of maternal erythrocytes infected), or severe (>10\% maternal erythrocytes infected) in 20 40 fields at 40-100X magnification. Gravidity was categorized as primigravid (women's first pregnancy) or multigravid (women's second or later pregnancies). Low birth weight (LBW) infants weighed $<2500 \mathrm{~g}$.

\section{Clinical Data}

Prenatal care was available to women in both Bamako and the rural villages, although participation was uneven and often did not comply with WHO guidelines [13]. During antenatal care (ANC), Malian clinicians measured the mothers' height, weight, and blood pressure, estimated due dates, administered elemental iron, and low dose folic acid. They also administered SP, and we accessed data on SP dosing from patient medical records as opposed to using self-reports. A total of 232 of the 317 pregnancies in the analysis $(73.2 \%)$ included testing for HIV during prenatal exams and there was one positive result. Births were by vaginal delivery followed by administration of oxytocin to assist expulsion of the placenta. Birth parameters were measured by midwives immediately after birth and included newborn length, birth weight, and placenta weight. No births to women in the study took place outside of healthcare facilities.

\section{Covariates}

Page 3/19 
Data were collected by a trained team of Malian collaborators. Body mass index (BMI), educational attainment, and location of residence for each participant were obtained during the approximately annual follow-up of cohort members. Wealth z-scores were determined using a system of independent rankings by approximately five judges from each study village who ranked each family's wealth relative to that of other families in the same village. Residence was recorded as rural if the woman lived in one of the original villages or urban if she had moved to Bamako. Women who moved during gestation were classified in the location where they lived during the majority of their pregnancy. During annual interviews, no participants reported being smokers (current or past), in agreement with cultural norms for Dogon women and observations by the field team and authors (ZD, CV, BIS) who interacted regularly with these women.

\section{Statistical Analyses}

IBM SPSS v. 27 was used to generate risk factor models using general estimating equations (GEE) that took into account the nonindependence of maternal siblings. Binary dependent variables were PM and low birth weight (<2500 g). We also used logistic GEE models to assess the characteristics of women who were fully compliant with the policy that women should receive at least 3 doses of SP, as well to gain insight into the women who received no doses of SP. Continuous dependent variables were birth outcomes (birth weight, birth length, or placenta weight). $P$ values $<0.05$ were considered statistically significant. All models were adjusted for pertinent covariates as described below.

\section{Results}

\section{Study participant characteristics}

Descriptive statistics for the mothers, births, and for placental malaria are shown in Table 1 . Most placentas were from first births ( $56 \%$ of mothers were primigravida and $44 \%$ were multigravida) and the majority of mothers lived in rural villages on the Bandiagara Escarpment (84\% in villages, $16 \%$ in Bamako) during most of gestation (Table 1). Mean (SD) maternal age at delivery was $20.4 \pm 2.2$ years and mean pre-pregnancy BMI was $21.8 \pm 2.4$. Twenty-six percent of the births in the study were to mothers who reported no schooling, $38 \%$ reported some primary education, $25 \%$ reported some secondary education, and $11 \%$ reported some education beyond secondary school. Seven percent of the women received no doses of SP, $32 \%$ received one dose, $36 \%$ received two doses, and $25 \%$ received three or more doses of SP. The distribution of births by season was $45 \%$ in the rainy season, $30 \%$ in the cool dry season, and $25 \%$ in the hot dry season. The mean (SD) birth weight (g) was 2719 (405), birth length (cm) was 49.1 (1.7), and placenta weight (g) was 483 (91). Twenty-five percent of the neonates were of low birth weight $(<2500 \mathrm{~g})$ and $75 \%$ were of normal birth weight (Table 1$)$.

Table 1 Maternal, pregnancy, and birth characteristics (317 mother-offspring pairs) 


\begin{tabular}{|c|c|}
\hline Categorical Variables & $n(\%)$ \\
\hline Mothers & \\
\hline Residence during pregnancy & \\
\hline Bamako & $49(15.5)$ \\
\hline Village & $268(84.5)$ \\
\hline Education & \\
\hline No Schooling & $83(26.2)$ \\
\hline Some primary & $120(37.8)$ \\
\hline Some secondary & $80(25.2)$ \\
\hline Beyond secondary & $34(10.7)$ \\
\hline IPTp-SP doses & \\
\hline None & $21(6.6)$ \\
\hline 1 & $103(32.5)$ \\
\hline 2 & $115(36.3)$ \\
\hline $3+$ & $78(24.6)$ \\
\hline Parity & \\
\hline Primigravida & $176(55.5)$ \\
\hline Multigravida & $141(44.5)$ \\
\hline Births & \\
\hline Survival status & \\
\hline Survived & $310(97.8)$ \\
\hline Stillborn & $6(1.9)$ \\
\hline Missing & $1(0.3)$ \\
\hline Sex & \\
\hline Female & $150(47.3)$ \\
\hline Male & $167(52.7)$ \\
\hline Weight ${ }^{\mathrm{a}}$ & \\
\hline Low $(<2500 \mathrm{~g})$ & $78(25.2)$ \\
\hline Normal $(\geq 2500 \mathrm{~g})$ & $232(74.8)$ \\
\hline Season $(N=317)$ & \\
\hline Hot dry (Mar - May) & $79(25)$ \\
\hline Rainy (Jun - Oct) & $144(45.4)$ \\
\hline Cool dry (Nov - Feb) & $94(29.7)$ \\
\hline Year & \\
\hline 2011 & $2(0.6)$ \\
\hline 2012 & $1(0.3)$ \\
\hline 2013 & $1(0.3)$ \\
\hline 2014 & $38(12.0)$ \\
\hline 2015 & $42(13.2)$ \\
\hline 2016 & $64(20.2)$ \\
\hline 2017 & $71(22.4)$ \\
\hline 2018 & $68(21.5)$ \\
\hline 2019 & $30(9.5)$ \\
\hline Placental Malaria & \\
\hline Infection stage & \\
\hline None & $90(28.4)$ \\
\hline Acute & $17(5.4)$ \\
\hline Chronic & $55(17.4)$ \\
\hline Past & $149(47.0)$ \\
\hline Missing & $6(1.9)$ \\
\hline Parasite density & \\
\hline None & $241(76.0)$ \\
\hline Mild & $33(10.4)$ \\
\hline Moderate & $17(5.4)$ \\
\hline Severe & $21(6.6)$ \\
\hline Missing & $5(1.6)$ \\
\hline Quantitative Variables & mean $(\mathrm{SD})$ \\
\hline Maternal age at delivery (years) & $20.4(2.2)$ \\
\hline Maternal pre-pregnancy BMI & $21.8(2.4)$ \\
\hline Maternal wealth Z-score & $0.50(0.87)$ \\
\hline Birth weight $(\mathrm{g})^{\mathrm{a}}$ & 2719.1 (404.6) \\
\hline Birth length $(\mathrm{cm})^{\mathrm{a}}$ & $49.1(1.7)$ \\
\hline Placenta weight $(\mathrm{g})^{\mathrm{a}}$ & $483.2(90.9)$ \\
\hline
\end{tabular}

${ }^{a}$ for 310 livebirths. $B M I$, body mass index; $S D$, standard deviation

\section{PM prevalence in study specimens}

Of 317 placentas analyzed, 90 (28\%) had no indicators of active or past PM, and 6 (2\%) could not be scored (Table 1). Among the 72 (23\%) active PM infections, 17 were scored as acute (parasites but no hemozoin visible) and 55 were scored as chronic (hemozoin and parasites visible). There were 149 (47\%) past PM infections indicated by the presence of hemozoin but not parasites. Further, among the 317 placentas, $76 \%$ showed no evidence of malaria parasites, and $2 \%$ could not be scored. Parasitemia in the remaining samples was mild $10 \%$, moderate $5 \%$, and severe $7 \%$.

\section{Maternal risk factors for PM (active \& past Infections combined)}

Models of the risk factors for active and/or past PM infections are shown in Table 2. Models 1 and 2 differ in that model 2 omits year of offspring birth, which is correlated with maternal age (SI Figure 1). Maternal age was not associated with PM in Model 1. In Model 2, which excluded year of offspring birth, a one year increase in maternal age was associated with a $23 \%$ decrease ( $p=0.007$ ) in the odds of PM. A one unit increase in maternal pre-pregnancy BMI was associated with a $13 \%$ reduced odds $(p=0.048)$ of PM infection in Model 1 and a $9 \%$ reduced odds in Model 2 that was not statistically significant $(p=0.176)$. 
Table 2

Maternal risk factors for PM infection (active and past infections combined)

\begin{tabular}{|c|c|c|c|c|c|c|c|c|c|c|}
\hline & \multicolumn{5}{|c|}{ Model 1} & \multicolumn{5}{|c|}{ Model 2} \\
\hline & \multirow[t]{2}{*}{ B } & \multirow[t]{2}{*}{ OR } & \multicolumn{2}{|l|}{$95 \% \mathrm{Cl}$} & \multirow[t]{2}{*}{$p$-value } & \multirow[t]{2}{*}{ B } & \multirow[t]{2}{*}{ OR } & \multicolumn{2}{|l|}{$95 \% \mathrm{Cl}$} & \multirow[t]{2}{*}{ p-value } \\
\hline & & & Lower & Upper & & & & Lower & Upper & \\
\hline Intercept & 4.09 & 60.03 & 0.48 & 7506.45 & 0.096 & 8.34 & 4203.52 & 81.8 & 216007.64 & $<0.001$ \\
\hline Maternal age (years) & -0.01 & 0.99 & 0.79 & 1.23 & 0.908 & -0.26 & 0.77 & 0.64 & 0.93 & 0.007 \\
\hline Pre-pregnancy BMI & -0.14 & 0.87 & 0.76 & 1.00 & 0.048 & -0.09 & 0.91 & 0.79 & 1.04 & 0.176 \\
\hline \multicolumn{11}{|c|}{ Gravidity (ref. Multigravid) } \\
\hline Primigravid & 0.37 & 1.44 & 0.73 & 2.85 & 0.293 & 0.10 & 1.11 & 0.60 & 2.06 & 0.743 \\
\hline \multicolumn{11}{|l|}{ IPTp-SP Doses (ref. 3+) } \\
\hline None & 2.68 & 14.57 & 3.20 & 66.43 & $<0.001$ & 2.10 & 8.20 & 2.09 & 32.3 & 0.003 \\
\hline 1 & 0.72 & 2.06 & 0.96 & 4.43 & 0.064 & 0.83 & 2.29 & 1.14 & 4.57 & 0.019 \\
\hline 2 & 0.44 & 1.55 & 0.72 & 3.31 & 0.263 & 0.49 & 1.63 & 0.81 & 3.30 & 0.171 \\
\hline \multicolumn{11}{|c|}{ Residence during pregnancy (ref. Village) } \\
\hline Bamako & -1.10 & 0.33 & 0.14 & 0.81 & 0.015 & -1.11 & 0.33 & 0.15 & 0.71 & 0.005 \\
\hline Wealth z-score & 0.25 & 1.29 & 0.91 & 1.82 & 0.157 & 0.32 & 1.37 & 0.99 & 1.91 & 0.060 \\
\hline \multicolumn{11}{|c|}{ Education (ref. Never attended) } \\
\hline Primary & -0.63 & 0.53 & 0.24 & 1.19 & 0.126 & -0.46 & 0.63 & 0.30 & 1.32 & 0.221 \\
\hline Secondary & 0.29 & 1.33 & 0.54 & 3.31 & 0.537 & 0.15 & 1.16 & 0.51 & 2.65 & 0.727 \\
\hline Beyond secondary & -1.80 & 0.17 & 0.06 & 0.46 & 0.001 & -1.38 & 0.25 & 0.10 & 0.65 & 0.004 \\
\hline \multicolumn{11}{|c|}{ Season of birth (ref. Hot Dry, Mar - May) } \\
\hline Rainy, Jun - Oct & -1.45 & 0.23 & 0.09 & 0.58 & 0.002 & -0.37 & 0.69 & 0.34 & 1.39 & 0.302 \\
\hline Cool Dry, Nov - Feb & -0.81 & 0.45 & 0.18 & 1.10 & 0.081 & 0.02 & 1.02 & 0.46 & 2.25 & 0.961 \\
\hline \multicolumn{11}{|c|}{ Year of offspring birth (ref. 2018) } \\
\hline 2014 & 1.43 & 4.19 & 1.05 & 16.72 & 0.043 & & & & & \\
\hline 2015 & 2.10 & 8.16 & 2.32 & 28.67 & 0.001 & & & & & \\
\hline 2016 & 1.95 & 7.04 & 2.54 & 19.49 & $<0.001$ & & & & & \\
\hline 2017 & 0.91 & 2.50 & 1.00 & 6.25 & 0.051 & & & & & \\
\hline 2019 & -1.33 & 0.26 & 0.09 & 0.82 & 0.021 & & & & & \\
\hline
\end{tabular}

Primigravid women had a higher risk of PM than did multigravid women in both Model1 and 2, but the difference was not statistically significant. Gravidity was correlated with both maternal age and year of birth (SI Figure 2) such that if either variable was included in the model, gravidity was no longer significant. However, if we did not adjust for maternal age or year of offspring birth, then the odds of PM (active and past combined) was 1.88 fold higher $(p=0.023)$ in primigravida compared to multigravida (SI Table 1). Pre-pregnancy BMI (SI Figure 2) was not strongly associated with gravidity. Mean (SD) BMI in primigravida was 21.5 (2.4) and in the multigravida was 22.2 (2.5). In no model for active infections was gravidity significant $(p>0.5)$. 
Risk of PM in both models tended to increase as doses of SP received decreased. Compared to 3 or more doses of SP, getting no doses of SP was associated with fourteen-fold and eight-fold higher odds of PM in models 1 and 2, respectively (Model 1: OR = 14.57, $\mathrm{p}=0.001$; Model 2: $O R=8.20, p=0.003$ ). Receiving one dose instead of three doses was associated with an approximately two-fold higher odds of PM in both models (Model 1: OR $=2.06, p=0.064$; Model 2: OR $=2.29, p=0.019$ ), but this association was statistically significant only in Model 2. Women receiving two doses of SP compared to those receiving three doses had an approximately $50 \%$ increased odds of infection but this increase was not statistically significant in either model (Model 1: OR = 1.55, $p=0.263 ;$ Model 2: OR = 1.63, $p=0.171$ ).

Residence in Bamako instead of the villages during pregnancy was associated with 67\% lower odds of PM in both models, (Model 1: OR $0.33, p=0.015$, Model 2: OR 0.33, $p=0.005)$. Family wealth z-score was not significantly associated with the odds of placental malaria (Model 1: OR $=1.29, p=0.16$, Model 2: OR = 0.32, $p=0.06$ ). Compared with women who had no schooling, women who went beyond secondary school had 83\% and 75\% decreased odds of PM in Models 1 and 2, respectively (Model 1: OR = 0.17, p = 0.001, Model 2: OR = $0.25, p=0.004)$. Births during the rainy season compared to the hot dry season were associated with $77 \%$ decreased odds of PM in Model $1(p=0.002)$ and $31 \%$ decreased odds in model 2 that was not statistically significant $(p=0.30)$. The odds of PM for births occurring during cool dry months were not significantly different from the odds of PM for the hot dry months (Model 1: OR = 0.45, $p=0.081$, Model $2:$ OR $=1.02, p=0.961$ ). Compared with deliveries in 2018, births in 2014, 2015, 2016, and 2017 had two to eight-fold higher odds of PM and deliveries in 2019 had $74 \%$ lower odds of PM.

\section{Maternal Risk Factors for Active PM}

The risk factors for active PM are shown in Table 3. Model 4 differs from Model 3 in that it does not include year of offspring birth, which is correlated with maternal age (SI Figure 1), as discussed above. In Model 3, maternal age was not associated with active PM (OR = 0.96, $p=0.696)$. In Model 4, a one year increase in maternal age was associated with a $17 \%$ decrease $(O R=0.83, p=0.016)$ in the odds of active PM. Pre-pregnancy BMI, gravidity, wealth z-score, and education were not significantly associated with active PM in models 3 or 4. As was the case for active and past infections combined, the odds of active PM tended to increase as doses of SP received decreased. Compared with women who received three doses of SP, women who had no doses had ten-fold and six-fold higher odds of active PM in models 3 and 4, respectively (Model 3: OR $=10.50, p=0.001$; Model 4: OR $=5.90, p=0.008$ ) and women who had only one dose had more than two-fold higher odds of active PM (Model 3: OR = 2.64, $p=0.036$, Model 4: OR = 2.57, $p=0.030$ ). The difference between three doses and two doses was not statistically significant (Model 3: OR = 1.49, $p=0.411$; Model 4: OR = 1.35, $p=0.513$ ). 
Table 3

Maternal risk factors for active PM infection

\begin{tabular}{|c|c|c|c|c|c|c|c|c|c|c|}
\hline & \multicolumn{5}{|c|}{ Model 3} & \multicolumn{5}{|c|}{ Model 4} \\
\hline & \multirow[t]{2}{*}{$B$} & \multirow[t]{2}{*}{ OR } & \multicolumn{2}{|l|}{$95 \% \mathrm{Cl}$} & \multirow[t]{2}{*}{ p-value } & \multirow[t]{2}{*}{ B } & \multirow[t]{2}{*}{ OR } & \multicolumn{2}{|l|}{$95 \% \mathrm{Cl}$} & \multirow[t]{2}{*}{ p-value } \\
\hline & & & Lower & Upper & & & & Lower & Upper & \\
\hline Intercept & -2.86 & 0.06 & 0.00 & 7.03 & 0.244 & 1.18 & 3.25 & 0.06 & 182.08 & 0.566 \\
\hline Maternal age (years) & -0.04 & 0.96 & 0.79 & 1.17 & 0.696 & -0.19 & 0.83 & 0.71 & 0.96 & 0.016 \\
\hline Pre-pregnancy BMI & -0.03 & 0.97 & 0.84 & 1.11 & 0.640 & -0.03 & 0.97 & 0.83 & 1.12 & 0.670 \\
\hline \multicolumn{11}{|c|}{ Gravidity (ref. Multigravid) } \\
\hline Primigravid & -0.23 & 0.79 & 0.37 & 1.72 & 0.556 & -0.23 & 0.80 & 0.38 & 1.66 & 0.547 \\
\hline \multicolumn{11}{|l|}{ IPTp-SP doses (ref. 3+) } \\
\hline None & 2.35 & 10.50 & 2.65 & 41.63 & 0.001 & 1.77 & 5.90 & 1.60 & 21.78 & 0.008 \\
\hline 1 & 0.97 & 2.64 & 1.07 & 6.55 & 0.036 & 0.94 & 2.57 & 1.09 & 6.03 & 0.030 \\
\hline 2 & 0.40 & 1.49 & 0.57 & 3.88 & 0.411 & 0.30 & 1.35 & 0.55 & 3.29 & 0.513 \\
\hline \multicolumn{11}{|c|}{ Residence during pregnancy (ref. Village) } \\
\hline Bamako & -2.01 & 0.13 & 0.03 & 0.73 & 0.020 & -2.23 & 0.11 & 0.02 & 0.52 & 0.005 \\
\hline Wealth z-score & 0.22 & 1.25 & 0.87 & 1.80 & 0.230 & 0.23 & 1.26 & 0.90 & 1.76 & 0.184 \\
\hline \multicolumn{11}{|c|}{ Education (ref. Never attended) } \\
\hline Primary & -0.51 & 0.60 & 0.27 & 1.32 & 0.206 & -0.46 & 0.63 & 0.30 & 1.32 & 0.224 \\
\hline Secondary & -0.22 & 0.80 & 0.32 & 2.00 & 0.637 & -0.34 & 0.71 & 0.32 & 1.61 & 0.417 \\
\hline Beyond secondary & -0.53 & 0.59 & 0.18 & 1.88 & 0.371 & -0.38 & 0.68 & 0.22 & 2.13 & 0.511 \\
\hline \multicolumn{11}{|c|}{ Season of birth (ref. Hot Dry, Mar - May) } \\
\hline Rainy, Jun - Oct & 2.40 & 11.00 & 3.27 & 37.01 & $<0.001$ & 2.66 & 14.33 & 4.34 & 47.27 & $<0.001$ \\
\hline Cool Dry, Nov - Feb & 1.95 & 7.02 & 2.08 & 23.70 & 0.002 & 2.07 & 7.95 & 2.28 & 27.78 & 0.001 \\
\hline \multicolumn{11}{|c|}{ Year of offspring birth (ref. 2018) } \\
\hline 2014 & 1.61 & 4.98 & 1.47 & 16.88 & 0.010 & & & & & \\
\hline 2015 & 1.95 & 7.04 & 2.20 & 22.49 & 0.001 & & & & & \\
\hline 2016 & 1.59 & 4.90 & 1.62 & 14.86 & 0.005 & & & & & \\
\hline 2017 & 0.20 & 1.23 & 0.34 & 4.42 & 0.754 & & & & & \\
\hline 2019 & -0.19 & 0.82 & 0.08 & 8.61 & 0.871 & & & & & \\
\hline
\end{tabular}

For women who lived in Bamako instead of the villages during their pregnancies, the odds of active infections were $87 \%$ lower in Model 3 and $89 \%$ lower in model 4 (Model 3 : OR $=0.13, p=0.020$, Model 4: OR $=0.11, p=0.005$ ). Births during the rainy season were associated with eleven and fourteen times higher odds ratios for active PM compared to births in the hot dry season in models 3 and 4 , respectively (Model 3: OR $=11.00, p<0.001$, Model 4 OR $=14.33, p<0.001$ ). The odds of active PM were about five to seven-fold higher for births in 2014, 2015, and 2016 relative to 2018 .

\section{Associations between infection stage, parasite density, SP Doses, and birth outcomes}


Infection Stage. Models relating PM infection stage to birth outcomes (birth weight, birth length, and placenta weight) are shown in Table 4. All models adjust for maternal age and pre-pregnancy BMI, gravidity, sex of neonate, and residence (Bamako or village). If the placenta showed histological evidence of chronic infection $(N=55)$ as opposed to no infection $(N=90)$, birth weight was $313 \mathrm{~g}$ lower ( $\mathrm{p}<0.001)$, birth length was $0.66 \mathrm{~cm}$ shorter $(p=0.035)$, and placenta weight was $68 \mathrm{~g}$ lower $(p<0.001)$. Acute $(\mathrm{N}=17)$ and past infections $(\mathrm{N}=149)$ were not significantly associated with any of the three birth parameters.

Table 4

Associations between PM infection stage, parasite density, IPTp-SP doses, and birth outcomes

\begin{tabular}{|c|c|c|c|c|c|c|c|c|c|c|c|c|}
\hline & \multicolumn{4}{|c|}{ Birth weight (g) } & \multicolumn{4}{|c|}{ Birth Length (cm) } & \multicolumn{4}{|c|}{ Placenta weight (g) } \\
\hline \multicolumn{5}{|c|}{$95 \% \mathrm{Cl}$} & \multicolumn{4}{|c|}{$95 \% \mathrm{Cl}$} & \multicolumn{4}{|c|}{$95 \% \mathrm{Cl}$} \\
\hline & $\mathrm{B}$ & Lower & Upper & $\begin{array}{l}\mathrm{p}- \\
\text { value }\end{array}$ & $\mathrm{B}$ & Lower & Upper & $\begin{array}{l}\mathrm{p}- \\
\text { value }\end{array}$ & B & Lower & Upper & $\begin{array}{l}\mathrm{p} \text { - } \\
\text { value }\end{array}$ \\
\hline Intercept & 2714.00 & 2068.13 & 3359.87 & $<0.001$ & 50.31 & 47.61 & 53.00 & $<0.001$ & 509.85 & 377.47 & 642.24 & $<0.001$ \\
\hline \multicolumn{13}{|c|}{ Infection stage (ref. None) } \\
\hline Acute & 32.85 & -139.64 & 205.34 & 0.709 & 0.06 & -0.58 & 0.70 & 0.864 & 15.24 & -30.91 & 61.39 & 0.518 \\
\hline Chronic & -313.05 & -437.31 & -188.80 & $<0.001$ & -0.66 & -1.26 & -0.05 & 0.035 & -67.68 & -97.54 & -37.82 & $<0.001$ \\
\hline Past & -31.58 & -120.69 & 57.53 & 0.487 & 0.07 & -0.37 & 0.51 & 0.755 & -21.11 & -44.90 & 2.68 & 0.082 \\
\hline Intercept & 2668.52 & 2049.63 & 3287.40 & $<0.001$ & 50.42 & 47.77 & 53.07 & $<0.001$ & 486.18 & 355.70 & 616.66 & $<0.001$ \\
\hline \multicolumn{13}{|c|}{ Parasite density (ref. None) } \\
\hline Mild & -80.40 & -229.30 & 68.50 & 0.290 & -0.28 & -0.90 & 0.34 & 0.380 & -20.21 & -51.52 & 11.10 & 0.206 \\
\hline Moderate & -228.50 & -414.32 & -42.68 & 0.016 & -.09 & -0.88 & 0.71 & 0.830 & -39.58 & -84.26 & 5.10 & 0.082 \\
\hline Severe & -410.35 & -548.07 & -272.64 & $<0.001$ & -1.37 & -2.12 & -0.63 & $<0.001$ & -64.96 & -101.39 & -28.53 & $<0.001$ \\
\hline Intercept & 2592.50 & 2014.19 & 3170.81 & $<0.001$ & 50.78 & 48.46 & 53.11 & $<0.001$ & 512.92 & 382.67 & 643.16 & $<0.001$ \\
\hline \multicolumn{13}{|c|}{ IPTp-SP doses (ref. 3+) } \\
\hline none & -284.72 & -545.65 & -23.79 & 0.032 & -2.04 & -3.43 & -0.65 & 0.004 & -75.39 & -124.16 & -26.62 & 0.002 \\
\hline 1 & -75.49 & -185.82 & 34.83 & 0.180 & -0.49 & -1.00 & 0.03 & 0.064 & -31.69 & -58.53 & -4.84 & 0.021 \\
\hline 2 & -67.89 & -165.11 & 29.33 & 0.171 & -0.07 & -0.50 & 0.37 & 0.770 & -35.52 & -60.34 & -10.71 & 0.005 \\
\hline
\end{tabular}

Parasite Density. When parasite density was severe as opposed to no parasites observed, birth weight was $410 \mathrm{~g}$ lighter ( $\mathrm{p}<0.001)$, birth length was $1.4 \mathrm{~cm}$ shorter $(\mathrm{p}<0.001)$, and placenta weight was $65 \mathrm{~g}$ lighter $(\mathrm{p}<0.001)$. Moderate parasite densities were not associated with birth length $(p=0.83)$ or placental weight $(p=0.082)$, but were associated with lower birth weight by $228 \mathrm{~g}(p=0.016)$. Mild parasite densities were not statistically distinguishable from no parasites observed for all three birth outcomes $(p>0.2)($ Table 4$)$.

SP Doses. Compared with births to women who received at least three doses of SP, newborns from women who received no doses of SP were $285 \mathrm{~g}$ lighter $(p=0.032), 2 \mathrm{~cm}$ shorter $(p=0.004)$, and their placentas were $75 \mathrm{~g}$ lighter $(p=0.002)$. Placentas from women who received one or two doses of SP were $32 \mathrm{~g}$ lighter $(p=0.021)$ and $36 \mathrm{~g}$ lighter $(p=0.005)$, respectively, compared to placentas from women who received three or more doses of SP. Birth weight was lower for women who received one or two doses of SP compared to three or more doses but the difference was not statistically significant ( $p \geq 0.17)$. There was a trend toward shorter birth lengths by half a centimeter if the mother received one instead of at least three doses of SP $(B=-0.49, p=0.064)$, but no evidence for a difference at two doses instead of three or more $(B=-0.07, p=0.770)($ Table 4$)$.

When birth weight was modelled as a dichotomous instead of a continuous variable, chronic infections were associated with a $46 \%$ increase in the odds of LBW $(\mathrm{OR}=1.46, \mathrm{p}<0.001)$ and moderate and severe parasite densities were associated with a 35\% $(0 \mathrm{R}=1.35, \mathrm{p}=$ $0.016)$ and $71 \%(O R=1.71, p<0.001)$ increase in the odds of LBW, respectively. Receiving only one or two doses of SP compared with 
three doses was associated with a $14 \%$ increase in the odds of LBW (one dose: $O R=1.14, p=0.023$; two doses: $O R=1.14, p=0.015$ ) (Table 5).

Table 5

Associations between PM stage, parasite density, doses of IPTp-SP, and low birth weight $(<2500 \mathrm{~g})$

\begin{tabular}{|c|c|c|c|c|c|}
\hline & \multicolumn{5}{|c|}{$95 \% \mathrm{Cl}$} \\
\hline & B & OR & Lower & Upper & $\mathrm{p}$-value \\
\hline Intercept & -0.42 & 0.66 & 0.35 & 1.25 & 0.200 \\
\hline \multicolumn{6}{|c|}{ Infection stage (ref. None) } \\
\hline Acute & 0.09 & 1.10 & 0.88 & 1.37 & 0.398 \\
\hline Chronic & 0.38 & 1.46 & 1.25 & 1.70 & $<0.001$ \\
\hline Past & 0.09 & 1.10 & 0.99 & 1.21 & 0.068 \\
\hline Intercept & -0.28 & 0.76 & 0.41 & 1.40 & 0.377 \\
\hline \multicolumn{6}{|c|}{ Parasite density (ref. None) } \\
\hline Mild & 0.05 & 1.05 & 0.90 & 1.24 & 0.534 \\
\hline Moderate & 0.30 & 1.35 & 1.06 & 1.72 & 0.016 \\
\hline Severe & 0.53 & 1.71 & 1.41 & 2.06 & $<0.001$ \\
\hline Intercept & -0.17 & 0.84 & 0.45 & 1.57 & 0.590 \\
\hline \multicolumn{6}{|c|}{ IPTp-SP doses (ref. 3+) } \\
\hline None & 0.20 & 1.22 & 0.96 & 1.55 & 0.100 \\
\hline 1 & 0.13 & 1.14 & 1.02 & 1.28 & 0.023 \\
\hline 2 & 0.13 & 1.14 & 1.03 & 1.27 & 0.015 \\
\hline
\end{tabular}

\section{Predictors of SP doses}

We modeled both the odds for a woman to get no doses of SP, representing poor compliance with Malian national policy (Table 6: Model 5 ), and the odds for her to get $\geq 3$ doses, indicative of the best compliance (Table 6: Model 6 ). Women who were one year older were $28 \%$ less likely to get no doses of SP ( $p=0.04)$, and if they attended primary school instead of no school, they were $81 \%$ less likely to get no doses of SP ( $p=0.03$ ). If they gave birth in 2016 (as compared to 2018), they were 79\% less likely to get no doses of SP ( $p=0.03$ ) (Table 6: Model 5). The only variable that predicted getting $\geq 3$ doses of SP was wealth (Table 6 : Model 6). A one standard deviation increase in the wealth z-score of a woman's family was associated with $40 \%$ higher odds $(p=0.04)$ of receiving $\geq 3$ doses of SP compared to $<3$ doses (Table 6: Model 6), but other characteristics of the mother (age, pre-pregnancy BMI, gravidity, residence, education) were not significantly associated with dosing in this model. 
Table 6

Maternal and other characteristics associated with the number of SP doses received during pregnancy. Model 5 (poor compliance): No doses versus $1+$ doses. Model 6 (best compliance): $3+$ versus $<3$ doses

\begin{tabular}{|c|c|c|c|c|c|c|c|c|c|c|}
\hline & \multicolumn{5}{|c|}{ Model 5} & \multicolumn{5}{|c|}{ Model 6} \\
\hline & \multicolumn{4}{|c|}{$95 \% \mathrm{Cl}$} & \multirow[b]{2}{*}{$\mathrm{p}$-value } & \multirow[b]{2}{*}{ B } & \multirow[b]{2}{*}{ OR } & \multicolumn{2}{|l|}{$95 \% \mathrm{Cl}$} & \multirow[b]{2}{*}{$\mathrm{p}$-value } \\
\hline & B & OR & Lower & Upper & & & & Lower & Upper & \\
\hline Intercept & 4.17 & 64.73 & 0.06 & 64824.15 & 0.237 & -1.38 & 0.25 & 0.01 & 9.71 & 0.460 \\
\hline Maternal age (years) & -0.33 & 0.72 & 0.52 & 0.98 & 0.037 & -0.05 & 0.95 & 0.81 & 1.11 & 0.520 \\
\hline Pre-pregnancy BMI & 0.03 & 1.03 & 0.82 & 1.30 & 0.773 & 0.05 & 1.06 & 0.94 & 1.19 & 0.385 \\
\hline \multicolumn{11}{|c|}{ Gravidity (ref. Multigravid) } \\
\hline Primigravid & -0.50 & 0.61 & 0.18 & 2.05 & 0.422 & -0.11 & 0.90 & 0.49 & 1.65 & 0.733 \\
\hline \multicolumn{11}{|c|}{ Residence during pregnancy (ref. Village) } \\
\hline Bamako & -0.92 & 0.40 & 0.08 & 2.06 & 0.273 & 0.27 & 1.31 & 0.64 & 2.72 & 0.460 \\
\hline Wealth z-score & -0.31 & 0.73 & 0.42 & 1.27 & 0.267 & 0.34 & 1.40 & 1.02 & 1.92 & 0.036 \\
\hline \multicolumn{11}{|c|}{ Education (ref. Never attended) } \\
\hline Primary & -1.66 & 0.19 & 0.04 & 0.83 & 0.027 & 0.35 & 1.42 & 0.69 & 2.91 & 0.339 \\
\hline Secondary & -0.54 & 0.58 & 0.17 & 1.97 & 0.385 & 0.35 & 1.42 & 0.66 & 3.06 & 0.369 \\
\hline Beyond secondary & 0.90 & 2.45 & 0.64 & 9.46 & 0.193 & 0.22 & 1.25 & 0.49 & 3.19 & 0.640 \\
\hline \multicolumn{11}{|c|}{ Season of birth (ref. Hot Dry, Mar - May) } \\
\hline Rainy, Jun - Oct & 0.90 & 2.45 & 0.45 & 13.36 & 0.300 & -0.07 & 0.93 & 0.46 & 1.90 & 0.839 \\
\hline Cool Dry, Nov - Feb & 1.66 & 5.28 & 1.00 & 28.02 & 0.051 & -0.33 & 0.72 & 0.35 & 1.47 & 0.364 \\
\hline \multicolumn{11}{|l|}{ Year of birth (ref. 2018) } \\
\hline 2014 & -1.83 & 0.16 & 0.02 & 1.26 & 0.082 & -0.23 & 0.80 & 0.30 & 2.13 & 0.652 \\
\hline 2015 & -1.16 & 0.31 & 0.06 & 1.73 & 0.184 & -0.33 & 0.72 & 0.27 & 1.89 & 0.502 \\
\hline 2016 & -1.56 & 0.21 & 0.05 & 0.84 & 0.028 & -0.35 & 0.70 & 0.30 & 1.63 & 0.413 \\
\hline 2017 & -1.42 & 0.24 & 0.05 & 1.09 & 0.064 & -0.31 & 0.73 & 0.32 & 1.68 & 0.464 \\
\hline 2019 & 0.19 & 1.22 & 0.28 & 5.23 & 0.794 & 0.63 & 1.87 & 0.69 & 5.09 & 0.221 \\
\hline
\end{tabular}

\section{Discussion}

Rural versus Urban Residence. We evaluated placental malaria (PM) in 317 singleton births to 249 mothers who participated in a longitudinal cohort in a rural community on the Bandiagara Escarpment in Central Mali. Eight-four percent of the births were to women who continued to live in the rural community where they were followed from enrollment (1998 to 2000) to the time they gave birth (2011 to 2019). Fifteen percent of the births were to women in the cohort who had migrated to Bamako. The odds of a placenta being infected with malaria (including both active and past infections) were $67 \%$ lower $(p=0.015)$ for Bamako compared to the villages-after adjusting for other covariates such as the number of SP doses the woman received during pregnancy. Similarly, the prevalence of $P$. falciparum in children aged 6 to 59 months was far higher in the Mopti Region than in Bamako in the Demographic and Health Surveys in the years 2010 to 2018 [9]. Prevalence of malaria is generally higher in rural compared to urban areas [14, 15], although a few studies reported no difference between rural and urban locations $[16,17]$. We did not investigate differences in infrastructure, or social, and environmental factors that might contribute to the lower prevalence of placental malaria in Bamako. However, one advantage of our study is that the women at both locations came from the same ethnicity (Dogon), reducing genetic or cultural differences that may influence malaria susceptibility. Moreover, as they came from the same cohort, they were similar in age and shared similar childhood and adolescent 
environments prior to the migration, at a mean (SD) age of 17.9 (3.1) years, of some of the women to Bamako who then provided $16 \%$ of placentas analyzed.

PM Prevalence. The overall prevalence of PM in our study was 71\%, similar to other regions in Sub-Saharan Africa where malaria is endemic (for example, 75\% in southeastern Tanzania [18], 59\% in Sudan [19]). The prevalence of past infections, at 48\% in our study, was higher than for acute (5\%), chronic (18\%), and no (29\%) infection. Malaria parasites were not detected in most placentas (77\%), and when they were detected, the infections were mostly mild as opposed to moderate or severe, similar to a study in Kenya [20] that also used scoring criteria based on Bulmer et al. (1993) and Muehlenbachs (2010). We are not aware of any other studies conducted in Mali that examined PM prevalence using placental tissue histology, although several have used placental blood smears [21-23].

Risk Factors for PM. Several variables were strongly associated with PM. In particular, the odds of placental malaria infection were much higher for births to women in the earlier years of the study compared with the later years, which may have reflected increased anti-malaria efforts over time. For example in 2015, the odds for malaria infection (active and past combined) in our study were eight-fold higher ( $p=$ 0.001) than in 2018. In 2015, the Mopti Region had twice the malaria prevalence, compared to the national average, for children under five years, prompting an indoor residual spraying program which took place in 2017 and included the Bandiagara district [24]. From 2016 to 2017 , peak malaria incidence decreased by $42 \%$, on average, in sprayed health facility catchment areas compared to non-sprayed communities in the Mopti Region [24]. Spraying campaigns also took place in 2018 [25] and 2019 [26]. Our data provide further evidence for the success of malaria control campaigns on the Bandiagara escarpment.

[27].

Maternal Age and Year of Offspring Birth. Maternal age has sometimes been reported to be associated with PM [28] and a study in the District of Bandiagara in 1993 and 1994 reported that women under the age of 27 years had more malaria parasites in blood smears [29]. However, we found that after adjusting for year of study in an attempt to control for changes in yearly exposure to malaria, maternal age was no longer associated with PM (Table 2 and 3). Although maternal age and the year in which a woman gave birth are correlated, our analysis indicates that birth year was the more important predictor of PM in our study. As it was important to adjust for offspring's birth year, we will focus our discussion on the model for maternal risk factors for PM that did so (Model 1). We also note that since we identified far more past infections than active ones (acute and chronic), we had more statistical power to detect risk factors for active and past infections combined than for active infections alone.

Gravidity. Previous studies reported greater PM risk among women who were primigravida [19, 30-32]. We replicated this finding for active and past PM infections only if maternal age and year of birth, which are associated with gravidity (SI Figure 2), were not included in the model (SI Table 1). It has been reported that the timing of malaria infection during pregnancy differentially impacts primigravid and multigravid women [33], but we cannot assess this possibility in our study as we did not collect data on the timing of infection.

Maternal BMI. In our study, a one unit increase in maternal pre-pregnancy BMI was associated with a $13 \%$ decrease in the odds of active and past PM (Table 2: Model 1). This result is unlikely to be due to confounding with gravidity because, although the multigravida had a mean BMI that was $0.7 \mathrm{~kg} / \mathrm{m}^{2}$ greater than for the primigravida (SI Figure 2), we adjusted for gravidity. In Tanzania, underweight women had decreased risk of sub-microscopic placental malaria infection, while overweight or obese women had higher odds of placental malaria by blood smear compared to normal weight women [34]. The authors speculated that iron deficiency in the underweight mothers may have protected them against PM. Anemia was common in our study, but most of the placentas were from women who had normal BMI (84.5\% normal $(\mathrm{N}=268), 4.1 \%$ underweight $(\mathrm{N}=13), 11.4 \%$ overweight/obese $(\mathrm{N}=36)$. One possibility is that women of higher BMI in our study were more sedentary and engaged in less outdoor manual labor and thus had less exposure to mosquitoes.

Maternal Education. Mothers in our study who had some education beyond secondary school had decreased risk of both active and past PM infections combined. Similarly, education has been reported to be associated with decreased risk of malaria in pregnancy [35, 36]. However, associations between education and PM were not found in Uganda [35] and Sudan [19]. Education has been associated with health-seeking behaviors such as prenatal visits and optimal SP dosing [37]. As our models adjust for SP dosing, it is also possible that the better educated mothers performed less manual outdoor labor and had less exposure to mosquitoes.

Season of Birth. The odds of PM (active and past infections combined) were $77 \%$ lower for births in the rainy season (June through October) compared to the hot dry season (March through May) (Table 2: Model 1). Similarly, in The Gambia and Burkina Faso, risk for active and past PM was lower for births in the rainy season compared to the dry season [38]. In our study, the odds of active PM infections (excluding past infections) were eleven-fold greater for births during the rainy and seven-fold greater for births during the cool dry season compared to births in the hot dry season (Table 3: Model 3). This result may reflect increased transmission of malaria during the rainy

Page 12/19 
season, instigating active infections. Similarly, using thick blood smears, increased PM was found in the rainy season in univariate analyses for Koro and Bandiagara in Mali [23].

SP Doses. The 2018-2022 National Strategy for Malaria Control in Mali calls for at least $80 \%$ of pregnant women to receive $\geq 3$ doses three doses of sulfadoxine-pyrimethamine (SP) during their pregnancies [39]. At least 3 SP doses have been recommended to support and protect the period of rapid fetal weight gain during the third trimester [23] and have been associated with full term births and normal birth weights [40]. However, in our study, only $25 \%$ of women received $\geq 3$ doses of SP, $36 \%$ received two doses, $32 \%$ received one dose, and $7 \%$ received no doses of SP. Thus dosing of SP fell far short of national guidelines.

Across several regions of Mali in 2015, 66\% of women reported taking SP during pregnancy. Of those who took SP, $63 \%$ reported < 2 and $37 \%$ reported taking $\geq 3$ doses [41]. Compared with that study, our cohort had a lower prevalence of women who received no doses or who received $\geq 3$ doses of SP. Moreover, in our study, the first SP dose occurred late in pregnancy at a mean (SD) gestational age of about 26 (10) weeks, which is at the end (week 26) rather than the beginning (week 13) of the second trimester when dosing can begin. Late first SP doses (after 21 weeks) may provide suboptimal protection against infection as was seen in Benin [42]. In rural northern Ghana, women who had a second dose of SP during the 2nd trimester were more likely to receive $\geq 3$ doses compared to women whose first dose was delayed to the third trimester [40]. We did not detect a difference in dosing in Bamako compared to the villages; thus it would be a useful precaution for dosing at both sites to start earlier in the second trimester of pregnancy.

We tested for differences in the number of SP doses women received and the odds that a placenta was infected by malaria. Compared with mothers who received $\geq 3$ doses of SP, placentas from mothers who received no doses had fourteen-fold higher ( $p=0.001)$ odds of active and past PM. This was a stark difference. The odds for active (excluding past) infections were ten-fold higher ( $p=0.001)$ for women who had no doses and more than two-fold higher for women who had one dose $(p=0.036)$ compared to $\geq 3$ doses. However, regardless of whether we lumped active and past infections together or considered only active infections, we did not detect a difference in the odds of PM between receipt of 2 versus $\geq 3$ SP doses. This finding contrasts with an earlier study in 2006-2008 in the Segou Region of Mali which demonstrated two-fold lower prevalence of PM by placental blood smear with 3 SP doses compared to 2 doses after adjustment for gravidity, season of birth, maternal age, and malaria at enrollment [22]. A meta-analysis of 6 sub-Saharan countries found a $49 \%$ reduced risk of PM with $\geq 3$ compared to 2 SP doses [43], but this finding was restricted to primigravid and secundigravid women and did not pertain to multigravid women. In a Tanzanian low malaria transmission setting, no difference in PM was found for women who had $\geq 3$ doses compared to 2 doses [44]. The Tanzanian study also found a $36 \%$ increased risk of maternal anemia in women with 2 SP doses compared to $\geq 3$, highlighting the drug's role in combating malaria in the peripheral blood.

Birth Outcomes and SP Doses. We also examined birth outcomes in relation to the number of SP doses a pregnant woman received (Table 4). Compared with women who received $\geq 3$ doses, birth weight was lower by $285 \mathrm{~g}(\mathrm{p}=0.03)$ in women who received no doses of SP. It was lower by 75 and $68 \mathrm{~g}$ in women who received one or two doses, respectively, but these latter two differences were not statistically significant $(p>0.17)$ compared with $\geq 3$ doses. When we dichotomized birth weight as low versus normal, the risk of low birth weight (LBW) was $14 \%$ higher with one and two SP doses compared to $\geq 3$ doses $(p=0.02)$ and $22 \%$ higher with no doses versus $\geq 3$ but the $p$ value was 0.1 for this last comparison.

In South West Cameroon, $\geq 3$ doses were associated with lower odds of LBW compared to $\leq 1$ dose, but unlike our study, no difference was detected between $\geq 3$ doses and 2 doses [45]. In Southeast Tanzania, higher birth weight was seen with $\geq 3$ doses compared to two doses, as well as lower risk of LBW [46]. Lower risk of LBW was also seen in Nigeria with 3 doses compared to 2 doses [47]. A metaanalysis showed a stronger association between mean birth weight and 3 doses than mean birth weight and 2 doses [43]. Our study did not detect higher birth weights when women received $\geq 3$ compared to 2 doses, but did show increased risk of LBW with 2 compared to $\geq$ 3 doses. A topical review of LBW in Eastern Africa [48] found $\geq 3$ doses SP was associated with a decreased risk of LBW and increased birth weight compared to 2 doses. This review also addressed evidence that SP may not protect against risk of LBW in areas of high-level SP resistance. Parasite molecular markers demonstrating SP resistance were associated with decreased effectiveness of SP in preventing malaria infections and LBW in a meta-analysis of 57 studies in sub-Saharan Africa [49]. SP resistance in Mali increased $7 \%$ from 20002020 [50], a rate lower than some East African countries such as Mozambique (64\%) and Tanzania (55\%) but higher than other West African countries such as Nigeria (-14\%) and Burkina Faso (0.13\%).

In our study, birth length was $2 \mathrm{~cm}$ shorter $(p=0.004)$ when no SP doses were received compared to $\geq 3$ doses. We observed a trend toward shorter birth length by half a centimeter for one instead $\geq 3$ doses $S P(B=-0.49, p=0.064)$, but no evidence for a difference at two doses instead of $\geq 3$ doses $(B=-0.07, p=0.770)$. In Ghana doses even in excess of 5 were not associated with a dichotomous variable for birth length [40]. In Malawi, the child's length at 4 weeks of age was greater if the mother received SP doses on a monthly as opposed to an intermittent basis [51].

Page 13/19 
Placental Weight. The mean (SD) placental weight in our study was $483 \mathrm{~g}(91)$. We found that placentas were $75 \mathrm{~g}$ lighter $(\mathrm{p}=0.002)$ from women who received no SP doses compared to $\geq 3$ doses. Placentas from women who received one or two doses were $32 \mathrm{~g}$ lighter ( $\mathrm{p}=$ 0.021 ) and $36 \mathrm{~g}$ lighter ( $p=0.005)$, respectively, compared to placentas from women who received $\geq 3$ doses. Thus, placental weight was higher at any level of dosing, compared to no dosing, and we could distinguish one or two doses from three doses but not one dose from two doses. In southern Mozambique, placental weight was $49 \mathrm{~g}$ heavier and the duration of pregnancy was 6.1 days longer in women who had two SP doses compared to no doses [52]. Elsewhere, the impact of SP dosing on placental weight is largely unreported, although malaria infections in peripheral blood early in pregnancy were associated with decreased placental weight compared to uninfected controls in Tanzania [53].

SP Uptake. We attempted to discover why some women in our study received no doses of SP (Table 6: Model 5), which put their offspring at high risk for poor birth outcomes. We detected that these women were younger and they were more likely to have no education instead of having gone to primary school. These results underscore the importance of primary school education for women. This finding was similar to results from survey data from twelve sub-Saharan African countries including Mali in the years 2015-2019, showing maternal education and maternal age positively associated with SP doses [28]. We also identified a trend toward 5 times increased odds of receiving no SP doses $(p=0.06)$ if the birth was in the cool dry season instead of the hot dry season. Further research would be needed to understand whether this seasonal difference is real and, if applicable, any underlying causes. One possibility is that this finding might reflect seasonal differences in women's workload impinging on their time and energy to seek ante-natal care. Women who gave birth in 2018 as opposed to 2016 were more likely to get no doses of SP, which is surprising and bears further investigation.

In our study, socio-economic status was the only variable that predicted getting $\geq 3$ doses of SP. Specifically, for each additional increase in the wealth z-score of a woman's family, the woman was $40 \%$ more likely to receive $\geq 3$ doses of SP (Table 6: Model 6). A study conducted on the Bandiagara escarpment in Mali in 2015 [41] reported that women under age 20 years were less likely to receive $\geq 3$ doses of SP. That study [41] was consistent with ours in not finding an association between SP and urban/rural residence, but it differed in that it did not find an association between maternal education or wealth and SP doses. Similar to our findings, wealth was associated with $\geq 3$ doses of SP in Uganda [54] and Nigeria [55].

\section{Study limitations}

An important limitation of this study is its observational, non-randomized design. Therefore, to improve the comparison of PM in Bamako versus the villages, it was helpful that the participants in both places came from the same longitudinal cohort and the same ethnicity. Unlike most studies that entail an urban - rural comparison, our study was restricted to women who belonged to a specific cohort that we established in 1998 to 2000 in a rural community on the Bandiagara Escarpment. No placentas came from women who were not part of this cohort. Although the cohort study as a whole had unusually strong retention of participants who migrated to Bamako, losing only $6 \%$ of these urban migrants to follow-up, participation in the placental collections in Bamako was lower than in the villages. Placental collection in Bamako was logistically challenging as the women in the cohort gave birth at a variety of hospitals and clinics, whereas in the rural community only one hospital was involved.

Another limitation of our study is that we did not evaluate maternal anemia, which is known to be associated with malaria in pregnancy, and we did not measure peripheral blood parasitemia levels. Lastly, we assessed PM through the histological examination of the intervillous space of placental samples, which is an established method for assessment of PM. However, it is likely to miss early or low density (sub-microscopic) infections that would require molecular analysis for detection. We also lacked data on the onset of malarial infection, which would have been useful for shedding light on associations between placental malaria and season of birth.

\section{Conclusions}

We found that the odds of a placenta being infected with malaria were $67 \%$ lower in Bamako compared to a set of rural Dogon villages on the Bandiagara Escarpment in Mali. The women at both locations came from the same prospective cohort study, reducing confounding by genetic or cultural differences in vulnerability to malaria. Consistent with increased malaria control efforts on the Bandiagara escarpment, PM infection decreased substantially from 2014 to 2018. Women whose pre-pregnancy BMI was higher and who had some education beyond secondary school had decreased risk for PM. Only $25 \%$ of women received the recommended 3 or more doses of SP, and these women tended to come from wealthier families but were not more likely to live in Bamako. Thus in both locations, dosing of SP fell far short of national guidelines. We found a much greater improvement in birth outcomes $(+285 \mathrm{~g}$ birth weight, $+2 \mathrm{~cm}$ birth length, $+75 \mathrm{~g}$ placental weight) for women who had 3 doses of SP compared to no doses, but we did not detect a difference in birth weight or length for women who had 3 instead of 2 doses of SP. However at 2 instead of $\geq 3$ doses placentas were $36 \mathrm{~g}$ lighter and the odds of LBW as a

Page 14/19 
binary variable were $14 \%$ higher. Our study provides insight into how to locate the women who received no SP during pregnancy: they tended to be younger and to lack primary school education. Seeking out women who have these characteristics and promoting their access to antenatal care as early as possible in the second trimester will likely have a positive impact on birth outcomes. Our results show that it is also desirable for women to get $\geq 3$ doses, but high priority should be placed on improving access to antenatal care for women who otherwise will get no doses of SP. In this study such women comprised 7\% of our sample and had the poorest birth outcomes.

\section{Abbreviations}

ANC: antenatal care, IPTp-SP: Intermittent preventive treatment in pregnancy with sulfadoxine-pyrimethamine, PM: placental malaria, SP: sulfadoxine-pyrimethamine

\section{Declarations}

\section{Acknowledgements}

The authors thank the study participants who made this research possible as well as three Malian gynecologists for their advice and helpful suggestions: Prof. Amadou Dolo, Prof. Niani Mounkoro, and Prof. Mamadou Traoré. We also thank Christine Rysenga at the University of Michigan and the Malian medical team: Dr. Gouro Dicko, Dr. Akoro Dolo, Madeleine Goita, Aissa Dolo, Younus Dolo, Zeremi Sagara, and Safoura Guindo. For permission to carry out this study in Mali, we are grateful to the Centre National de la Recherche Scientifique et Technologique and the Comité d'Ethique de la Faculté de Médecine de Pharmacie et d'Onto-Stomatologie of the University of Sciences, Techniques, and Technologies of Bamako.

\section{Authors' contributions}

CV and BS conceived the study idea and designed the study; CV, ZD, SS, RL, and BS, acquired data; JL and BS carried out statistical analyses and wrote the manuscript. All authors read and approved the final manuscript.

\section{Funding}

This research was supported by the Eunice Kennedy Shriver National Institute of Child Health \& Human Development of the National Institutes of Health (R01HD088521 and R21HD077465 to BIS); the John Templeton Foundation (52269 to BIS); and the National Science Foundation program in Biological Anthropology (NSF BCS-1354814 to BIS). The content is solely the responsibility of the authors and does not necessarily represent the official views of the National Institutes of Health, the John Templeton Foundation, or the National Science Foundation.

\section{Availability of data and materials}

The dataset generated and analyzed during the current study will be made available at the National Institutes of Child Health and Human Development DASH data and specimen hub (https://dash.nichd.nih.gov) or a similar site upon publication.

\section{Ethics approval and consent to participate}

Informed consent or assent was obtained from participants depending on whether they were adults or children. IRB approval was obtained from the University of Michigan IRBMED (HUM00043670) and from La Faculté de Médecine de Pharmacie et d'Odontostomatologie (FMPOS) de Bamako in Mali (No2016/68/CD/FMPOS).

\section{Consent for publication}

Not applicable.

\section{Competing interests}

The authors declare that we have no competing interests.

\section{References}

1. WHO. World Malaria Report: 20 years of global progress and challenges. Geneva: World Health Organization; 2020. 
2. Guyatt HL, Snow RW. The epidemiology and burden of Plasmodium falciparum-related anemia among pregnant women in subSaharan Africa. Am J Trop Med Hyg. 2001;64(1,2)S:36-44.

3. WHO. World malaria report 2019. Geneva: World Health Organization; 2019.

4. Stevens GA, Finucane MM, De-Regil LM, Paciorek CJ, Flaxman SR, Branca F, et al. Global, regional, and national trends in haemoglobin concentration and prevalence of total and severe anaemia in children and pregnant and non-pregnant women for 1995-2011: a systematic analysis of population-representative data. Lancet Glob Heal. 2013;1:e16-25.

5. Kapisi J, Kakuru A, Jagannathan P, Muhindo MK, Natureeba P, Awori P, et al. Relationships between infection with Plasmodium falciparum during pregnancy, measures of placental malaria, and adverse birth outcomes. Malar J. 2017;16:400.

6. WHO. World malaria report: 2012. Generva: World Health Organization; 2012.

7. Menéndez C, Bardají A, Sigauque B, Sanz S, Aponte JJ, Mabunda S, et al. Malaria prevention with IPTp during pregnancy reduces neonatal mortality. PLoS One. 2010;5(2):e9438.

8. Cellule de Planification et de Statistique (CPS/SSDSPF), Institut National de la Statistique (INSTAT/MPATP), INFO-STAT et ICF International, 2014. Enquête Démographique et de Santé au Mali 2012-2013. Rockville, Maryland, USA : CPS, INSTAT, INFO-STAT et ICF International.

9. Koenker H, Coulibaly MK, Bouare I. DHS Further Analysis Report No. 132 Trends in and factors associated with malaria prevention in Mali: Further analysis of the Mali Demographic and Health Surveys and Malaria Indicator Surveys 2006-2018. 2020.

10. Vincenz C, Lovett JL, Wu W, Shedden K, Strassmann BI. Loss of imprinting in human placentas is widespread, coordinated, and predicts birth phenotypes. Mol Biol Evol. 2020;37:429-41.

11. Strassmann BI. Cooperation and competition in a cliff-dwelling people. Proc Natl Acad Sci U S A. 2011;108:10894-901.

12. Muehlenbachs A, Fried M, McGready R, Harrington WE, Mutabingwa TK, Nosten F, et al. A novel histological grading scheme for placental malaria applied in areas of high and low malaria transmission. J Infect Dis. 2010;202:1608-16.

13. Bulmer JN, Rasheed FN, Francis N, Morrison L, Greenwood BM. Placental malaria. I. Pathological classification. Histopathology. 1993;22:211-8.

14. Robert V, Macintyre K, Keating J, Trape JF, Duchemin JB, Warren M, et al. Malaria transmission in urban sub-Saharan Africa. Am. J. Trop. Med. Hyg. 2003;68(2):169-76.

15. Keiser J, Utzinger J, Caldas De Castro M, Smith TA, Tanner M, Singer BH. Urbanization in sub-Saharan Africa and implication for malaria control. Am J Trop Med Hyg. 2004;71:118-27.

16. Oringanje C, Meremikwu M, Ogar B, Okon A, Udoh A. Patterns of cord, placental and post-delivery maternal malaria parasitemia. Acta Obstet Gynecol Scand. 2010;89:1206-9.

17. Aribodor DN, Nwaorgu OC, Eneanya Cl, Okoli I, Pukkila-Worley R, Etaga HO. Association of low birth weight and placental malarial infection in Nigeria. J Infect Dev Ctries. 2009;3:620-3.

18. Ismail MR, Ordi J, Menendez C, Ventura PJ, Aponte JJ, Kahigwa E, et al. Placental pathology in malaria: A histological, immunohistochemical, and quantitative study. Hum Pathol. 2000;31:85-93.

19. Omer SA, Idress HE, Adam I, Abdelrahim M, Noureldein AN, Abdelrazig AM, et al. Placental malaria and its effect on pregnancy outcomes in Sudanese women from Blue Nile State. Malar J. 2017;16:1-8.

20. Shulman CE, Marshall T, Dorman EK, Bulmer JN, Cutts F, Peshu N, et al. Malaria in pregnancy: Adverse effects on haemoglobin levels and birthweight in primigravidae and multigravidae. Trop Med Int Heal. 2001;6:770-8.

21. Mahamar A, Andemel N, Swihart B, Sidibe Y, Gaoussou S, Barry A, et al. Malaria infection is common and associated with perinatal mortality and preterm delivery despite widespread use of chemoprevention in Mali: An observational study 2010 to 2014 . Clin Infect Dis. $2021 ; 73: 1355-61$.

22. Maiga OM, Kayentao K, Traoré BT, Djimde A, Traoré B, Diallo M, et al. Superiority of 3 over 2 doses of intermittent preventive treatment with sulfadoxine-pyrimethamine for the prevention of malaria during pregnancy in Mali: a randomized controlled trial. Clin Infect Dis. 2011;53:215-23.

23. Kayentao K, Mungai M, Parise M, Kodio M, Keita AS, Coulibaly D, et al. Assessing malaria burden during pregnancy in Mali. Acta Trop. 2007;102:106-12.

24. Wagman J, Cissé I, Kone D, Fomba S, Eckert E, Mihigo J, et al. Rapid reduction of malaria transmission following the introduction of indoor residual spraying in previously unsprayed districts: an observational analysis of Mopti Region, Mali, in 2017. Malar J. 2020;19:340.

25. The PMI VectorLink Project Mali, Annual Entomological Monitoring Report. January - December 2018. 2018. 
26. The PMI VectorLink Project. Mali End of Spray Report: July 1, 2019 - August 4, 2019. 2019.

27. Coulibaly D, Guindo B, Niangaly A, Maiga F, Konate S, Kodio A, et al. A Decline and Age shift in malaria incidence in rural Mali following implementation of seasonal malaria chemoprevention and indoor residual spraying. Am J Trop Med Hyg. 2021;104:13427.

28. Darteh EKM, Dickson KS, Ahinkorah BO, Owusu BA, Okyere J, Salihu T, et al. Factors influencing the uptake of intermittent preventive treatment among pregnant women in sub-Saharan Africa: a multilevel analysis. Arch Public Heal. 2021;79:1-9.

29. Dicko A, Mantel C, Thera MA, Doumbia S, Diallo M, Diakité M, et al. Risk factors for malaria infection and anemia for pregnant women in the Sahel area of Bandiagara, Mali. Acta Trop. 2003;89:17-23.

30. Zakama AK, Ozarslan N, Gaw SL. Placental Malaria. Curr. Trop. Med. Reports. 2020;7:162-71.

31. Fried M, Duffy PE. Malaria during pregnancy. Cold Spring Harb Perspect Med. 2017;7.

32. Rogerson SJ, Desai M, Mayor A, Sicuri E, Taylor SM, van Eijk AM. Burden, pathology, and costs of malaria in pregnancy: new developments for an old problem. Lancet Infect. Dis. 2018;e107-18.

33. Tran EE, Cheeks ML, Kakuru A, Muhindo MK, Natureeba P, et al. The impact of gravidity, symptomatology and timing of infection on placental malaria. Malar J. 2020;19:1-11.

34. Kalinjuma AV, Darling AM, Mugusi FM, Abioye Al, Okumu FO, Aboud S, et al. Factors associated with sub-microscopic placental malaria and its association with adverse pregnancy outcomes among HIV-negative women in Dar es Salaam, Tanzania: a cohort study. BMC Infect Dis. 2020;20:1-13.

35. Okiring J, Olwoch P, Kakuru A, Okou J, Ochokoru H, Ochieng TA, et al. Household and maternal risk factors for malaria in pregnancy in a highly endemic area of Uganda: A prospective cohort study. Malar J. 2019;18.

36. Gontie GB, Wolde HF, Baraki AG. Prevalence and associated factors of malaria among pregnant women in Sherkole district, Benishangul Gumuz regional state, West Ethiopia. BMC Infect Dis. 2020;20:1-8.

37. Hill J, Hoyt J, van Eijk AM, D’Mello-Guyett L, ter Kuile FO, Steketee R, et al. Factors affecting the delivery, access, and use of interventions to prevent malaria in pregnancy in sub-Saharan Africa: a systematic review and meta-analysis. PLoS Med. $2013 ; 10$.

38. Scott S, D'Alessandro U, Kendall L, Bradley J, Bojang K, Correa S, et al. Community-based malaria screening and treatment for pregnant women receiving standard intermittent preventive treatment with sulfadoxine-pyrimethamine: A multicenter (The Gambia, Burkina Faso, and Benin) cluster-randomized controlled trial. Clin Infect Dis. 2019;68:586-96.

39. USAID, CDC. U.S. President's Malaria Initiative Mali Malaria Operational Plan FY 2020. 2020.

40. Anto F, Agongo IH, Asoala V, Awini E, Oduro AR. Intermittent preventive treatment of malaria in pregnancy: assessment of the sulfadoxine-pyrimethamine three-dose policy on birth outcomes in rural Northern Ghana. J Trop Med. $2019 ; 2019$.

41. Diarra SS, Konaté D, Diawara SI, Tall M, Diakité M, Doumbia S. Factors associated with intermittent preventive treatment of malaria during pregnancy in Mali. J Parasitol. 2019;105:299-302.

42. Hounkonnou CPA, Ndam NT, Fievet N, Accrombessi M, Yovo E, Mama A, et al. Suboptimal intermittent preventive treatment in pregnancy (IPTp) is associated with an increased risk of submicroscopic Plasmodium falciparum infection in pregnant women: $\mathrm{A}$ prospective cohort study in Benin. Clin Infect Dis. 2020;

43. Kayentao K, Garner P, Van Eijk AM, Naidoo I, Roper C, Mulokozi A, et al. Intermittent preventive therapy for malaria during pregnancy using 2 vs 3 or more doses of sulfadoxine-pyrimethamine and risk of low birth weight in Africa: systematic review and meta-analysis. JAMA. 2013;309:594-604.

44. Mikomangwa WP, Minzi O, Mutagonda R, Baraka V, Mlugu EM, Aklillu E, et al. Effect of sulfadoxine-pyrimethamine doses for prevention of malaria during pregnancy in hypoendemic area in Tanzania. Malar J. 2020;19:1-11.

45. Anchang-Kimbi JK, Kalaji LN, Mbacham HF, Wepnje GB, Apinjoh TO, Ngole Sumbele IU, et al. Coverage and effectiveness of intermittent preventive treatment in pregnancy with sulfadoxine-pyrimethamine (IPTp-SP) on adverse pregnancy outcomes in the Mount Cameroon area, South West Cameroon. Malar J. 2020;19:1-12.

46. Mlugu EM, Minzi O, Asghar M, Färnert A, Kamuhabwa AAR, Aklillu E. Effectiveness of sulfadoxine-pyrimethamine for intermittent preventive treatment of malaria and adverse birth outcomes in pregnant women. Pathogens. 2020;9:1-19.

47. Igboeli NU, Adibe MO, Ukwe C V., Aguwa CN. Comparison of the effectiveness of two-dose versus three-dose sulphadoxinepyrimethamine in preventing adverse pregnancy outcomes in Nigeria. J Vector Borne Dis. 2018;55:189-96.

48. Bakken L, Iversen PO. The impact of malaria during pregnancy on low birth weight in East-Africa: a topical review. Malar J. 2021;20:19. 
49. van Eijk AM, Larsen DA, Kayentao K, Koshy G, Slaughter DEC, Roper C, et al. Effect of Plasmodium falciparum sulfadoxinepyrimethamine resistance on the effectiveness of intermittent preventive therapy for malaria in pregnancy in Africa: a systematic review and meta-analysis. Lancet Infect Dis. 2019;19:546-56.

50. Amimo F, Lambert B, Magit A, Sacarlal J, Hashizume M, Shibuya K. Plasmodium falciparum resistance to sulfadoxine-pyrimethamine in Africa: A systematic analysis of national trends. BMJ Glob Heal. 2020;5:1-12.

51. Luntamo M, Kulmala T, Cheung YB, Maleta K, Ashorn P. The effect of antenatal monthly sulphadoxine-pyrimethamine, alone or with azithromycin, on foetal and neonatal growth faltering in Malawi: A randomised controlled trial. Trop Med Int Heal. 2013;18:386-97.

52. Challis K, Osman NB, Cotiro M, Nordahl G, Dgedge M, Bergstrom S. Impact of a double dose of sulphadoxine-pyrimethamine to reduce prevalence of pregnancy malaria in southern Mozambique. Trop Med Int Heal. 2004;9:1066-73.

53. Schmiegelow C, Matondo S, Minja DTR, Resende M, Pehrson C, Nielsen BB, et al. Plasmodium falciparum infection early in pregnancy has profound consequences for fetal growth. J Infect Dis. 2017;216:1601-10.

54. Martin MK, Venantius KB, Patricia N, Bernard K, Keith B, Allen K, et al. Correlates of uptake of optimal doses of sulfadoxinepyrimethamine for prevention of malaria during pregnancy in East-Central Uganda. Malar J. 2020;19.

55. Ndu A, Mbachu C, Anitube O, Ezeoke U. Inequities in the use of sulphadoxine-pyrimethamine for malaria prophylaxis during pregnancy in Nigeria. Malawi Med J. 2020;32:45-51.

\section{Figures}

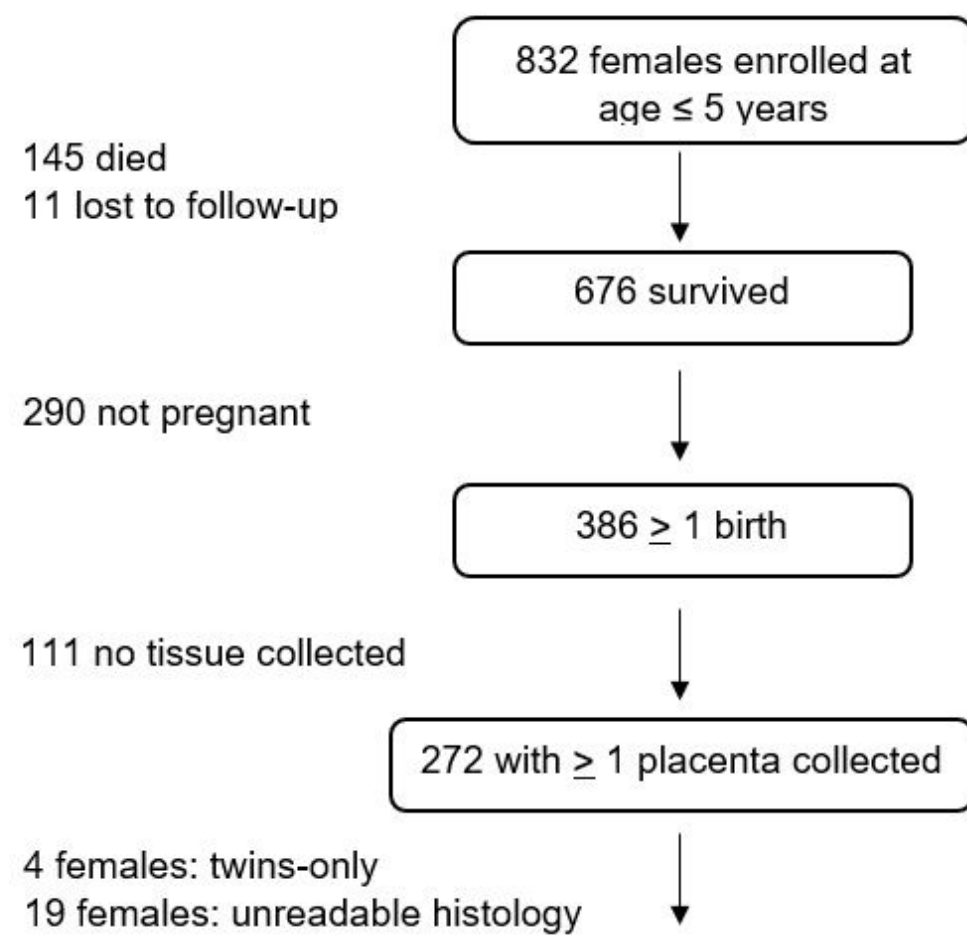
249 females with 317 placentas:
one placenta: 189
two placentas: 52
three placentas: 8

\section{Figure 1}

Profile of study mothers

Profile of females in the cohort study who were enrolled at age $\leq 5$ years and who survived to maturity and who contributed placentas for histological assessment. 


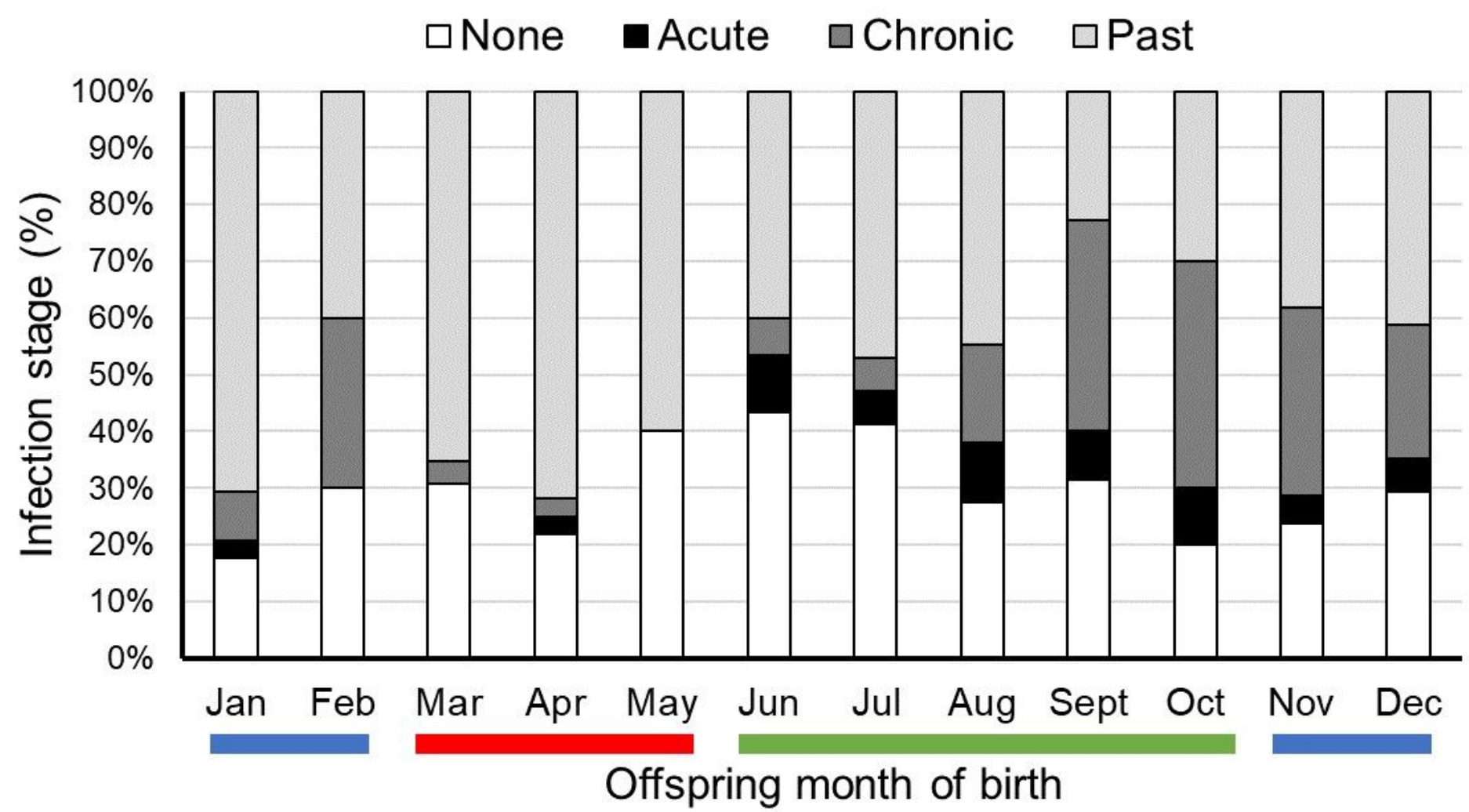

Figure 2

PM infection stages each offspring month of birth

PM infection stages each month of birth for all study years. Seasons are indicated by colored bars as cool/dry (blue), hot/dry (red), and rainy (green).

\section{Supplementary Files}

This is a list of supplementary files associated with this preprint. Click to download.

- SIFig1MatagebyDOB.docx

- SIFig2tripleboxplots.docx

- SITable1.docx 